OBSERVATIONS

\section{ON UTERINE PATHOLOGY AND TREATMENT.}

\section{B y R O B E R T B A R N E, M. D., XATE PHYSICIAN-ACCOUCHEUR TO THE WESTERT} CENERAL DISPENSARY.

Alrmovgr $I$ do not think that the now-debated questions of uterine pathology and treatment admit of being so easily settled as Dr. Boulton does, I do not feel myself at liberty to decline acceding to his appeal to state the result of my observations at the Western General Dispensary. It is a public institution. Like myself, Dr. Bennet conducted his practice there under the eyes of those of his professional brethren who wished to attend; and since Dr. Bennet, whose mode of treatment is the subject of controversy, himself challenges the testimony of those who have witessed his public practice, it is no breach of professional decorum to record my experience.

In doing this, $I$ cannot but express my regret that these topics should have been discussed with so much controversial passion as to deter many observers from stating their opinions, lest they should fall under the imputation of partizanship, and find themselves involved, not in the calm investigation of an abstract scientific problem, but in the unprofitable turmoil of personal disputations. I cannot but think that this circumstance has operated most injuriously in retarding the elucidation of many interesting and important questions in uterine pathology. One effect is, that almost all testimony bearing upon the points at issue is looked upon with some distrust. It is difficult in pursuing an inquiry into a subject so enveloped in, and obscured by, personal disputes, not to be led somewhat astray from the path of rigid induction.

It is, perhaps, still more difficult to obtain credit for having rigorously followed that path in a spirit of candour and independence; but, as $I$ am not conscious of having pursued it in any other spirit, although $I$ should have been willing to continue for some time longer to work in the field of observation before enunciating conclusions, $I$ do not hesitate in responding to the appeal that has been made to me. I feel, indeed, that I have no right to withhold my testimony. The evidence that peculiar opportunities have afforded me of giving upon the effects of the modes of treatment as advocated by Dr. Henry Bennet is, perhaps, more precise and extensive than any one else could give. I was the immediate successor of Dr. Bennet as physician-accoucheur to the Western General Dispensary. I held that office for four years. A considerable number of patients in course of treatment were transferred to me from the very hands of my predecessor. Many others who had been formerly treated by Dr. Bennet came to me at different periods for advice. Of the majority of cases I took notes, and I was especially careful to examine for traces of injurious effects of former cauterization. Although I had seen the acid nitrate of mercury, and even the actual cautery, freely used to the neck of the uterus at the Hôpital St. Louis, by M. Emery and M. Jobert de Lamballe, I was not without misgiving lest the use of potassa fusa, however cautiously applied, might cause such formidable loss of structure as even to deserve the name of mutilation. I proposed to myself two rules: to observe carefully the effects of nitrate of silver and potassa fusa cum calce upon the uterine structures, and to determine whether there were any, and what, morbid conditions of the cervix uteri that did not admit of cure without the use of canterization. The logical order would, of course, have been, to determine first how far cauterization might be dispensed with. But the opportunity of tracing the effect of the caustics named lay before me, by observing Dr. Bennet's patients. I will first state the result of my observations as to the action of potassa fusa. I copy from my notes the conditions of some cases in which I had especially recorded the state of the os and cervix uteri after the potassa fusa.

D - June 8th, 1850. This patient had been under Dr. Bennet since the preceding November. He had marked it, "Inflammation and extensive ulceration of neck of uterus;" potassa fusa had been applied twice. When I examined, the os was small, cervix not projecting, body of uterus expanded I and firm. It contained a fibrous tumour, which accounted for the effacement of cervix. There was some injection of os and cervix; no ulceration, and no mention of cicatrix, contraction, or loss of substance.

D__- June 20th, 1850. Had been under Dr. Bennet, who had applied potassa fusa. Now: inflammation of os ant cervical canal, with profuse leucorrhœa. After treatment, including cauterisations with nitrate of silver, os uteri reported " natural, slight redness, no abrasion." Got quite well and became pregnant.

J._. July 9th, 1850. Had been under Dr. Bennet, who had applied potassa fusa. Now: hypertrophy of cervix and hæmorrhagic menstruation. No mention of loss of structure of cervix.

W- June 25th, 1850. Long under Dr. Bennet; potassa fusa. A tight band stretching from posterior lip of os uteri to vagina, hardness all round, os somewhat congested. This might seem to be a case where the potassa fusa had really destroyed a. portion of the cervix : but shortly after this date the marks of cancer of the os and cervix were unmistakable; of this the patient died about a year afterwards.

S—_ June 27th, 1850. Potassa fusa by Dr. Bennet since January. Os small, high up, far back, small projections, feeling like peas on margin; no tenderness, no redness, no breach of surface.

P_- July 18th, 1850. Old patient of Dr. Bennet. Potassa fusa. Os small, firm; redness of os and cervix.

T_- July 27th, 1850. Long nnder Dr. Bennet. Potassa fusa. Inflammation and ulceration of os.

C-, August 17th, 1850. Formerly under Dr. Bennet, and cured. Potassa fusa. Now ill again : os red, inflamed; abrasion; thick yellow discharge from os; congestion ; small; irregular. The os became normal when cured.

W- August 29th, 1850. Under Dr. Bennet six months ago. Potassa fusa; was much relieved. Now: os large, irregular, open, hard, red, inflamed; erosion all round, and extending into cavity of cervix. After local and general treatment this os and cervix resumed a natural condition.

L-, August 29th, 1850. Relieved by Dr. Bennet. Potassa fusa. Now: redness of cervix and upper part of vagina; no ulceration.

J_, August 29th, 1850. Under Dr. Bennet for ten months, two years ago. Potassa fusa. Relieved. Now, os high, small, smooth, inflamed.

W-, January 30th, 1851. Sent to me by Mr. Langmore. Har been under Dr. Bennet a year ago. Potassa fusa. Got better. Now: os in normal position, tender; cerrix hard, small; circumscribed redness of os; two or three abraded spots, which bleed; os very small, admitting probe with difficulty.

M-, August 7th, 1851. Had a child after severe labour, four years ago; has suffered more from uterine symptoms since, but always had leucorrhoea and bearing-down; was formerly under Dr. Bennet. Potassa fusa. Got better. Now, pregnant four months. Edema of legs; health bad; cough, expectoration, night-sweats. Was under Dr. Miller in the winter. $\mathrm{Os}$, irregular, rough, open; anterior lip, prominent; cervix, hard, great inflammation; cavity of cervix, granular abrasion.

16th.-Profuse hæmorrhage.

Under cauterization and quinine, the local disease was cured, health rallied greatly, and she was delivered in December by me. Cervix expanded naturally. She did well. W-, October, 1852. Under Dr. Bennet two and a half years ago. Potassa, and actual cautery. Now: os very low, projecting; cervix presenting a mere pin-hole, no inflammation, pale, hard, somewhat enlarged, round and smooth. Came to me for severe uterine neuralgia on approach of menstruation. By general treatment, dilatation of cervix, and occasional use of nitrate of silver, the conical projection of this cervix disappeared, the opening of the os increased, and the vaginal portion of the uterus resumed its normal condition. Patient materially improved.

The above are the cases in which I find it especially stated that potassa fusa had been applied. In some of these, the fact that potasta fusa had been used was marked on the patients' letters by Dr. Bennet himself. In others, it was reported by the patient. I find that I have noted the circumstance of patients having been previously under Dr. Bennet's care in more than one hundred instances. I have no doubt that in many of these also the potassa fusa had been applied; but the information, I presume, was not sufficiently precise to lead me to record it. I have to state, that in none of these cases is any lesion or injury of the cervix uteri mentioned that was not accounted for by past or existing disease. 
That it is possible burn away the cervix uteri by the fer blanc, or to melt is away by potassa fusa, no one can doubt. The points to $_{0}$ cide are: whether these powerful surgical remedies are useful and necessary for the cure of particular morbid conditions of the uterus as they are found to be in morbid conditions of other parts of the body; and whether they admit of being used with safety, and in such a manner that we may be certain of limiting their action within the exact confines we wish. I have no hesitation in answering these questions in the affirmative. It is surely not a reasonable objection to urge that, unless great care be taken, the potassa fusa is apt to extend its action deeply into the substance of the cervix uteri, and to run down in a strong caustic solution into the vagina. No man solicitous for his patient or for himself employs powerful surgical agents without exercising great care. No operation in surgery ought to be performed without exercising the nicest judgment and delicacy of manipulation. The scalpel, as well as caustic, may, unless skilfully guided, wound too deeply. In advocating therefore the use of potassa fusa, it is assumed that it must be applied in proper cases only, and that with proper skill and precaution. 'The further action of potassa fusa may be instantly stopped by pressing a pledget of lint soaked in vinegar against the cauterized spot. If therefore grave accidents and mutilations, such as have been spoken of, have occurred, they must be ascribed to the want of judgment or of care on the part of the operator. Candour calls upon me to state that I have seen no such accidents or mutilations in Dr. Bennet's patients, nor have they occurred in my own practice. On referring, however, to the cases cited above, it will be seen that there is one accident liable to follow the use of potassa fusa, which it is necessary to guard against. When applied inside the canal of the cervix, an undue contraction or narrowing of the canal is apt to follow. It is necessary therefore to examine the patient carefully at times for some weeks after the operation, and to counteract this tendency by the occasional use of a bougie. For my own part, I have but very rarely applied the potassa fusa to the cervical cavity-perhaps less frequently than might have been done with advantage. But with regard to the value of this agent, when applied to the external surface of the portio vaginalis in certain cases of chronic inflammation, without hypertrophy and obstinate ulceration, I have, from my personal experience, formed a decided opinion. It is often urged that, in treating uterine diseases, local remedies being hardly ever resorted to alone, it is by no means a logical sequence that the recovery of patients is owing to the local remedies. The objection is not without force. It must, in very many cases, be a matter of great difficulty to determine whether the recovery was due to the general or to the local treatment, or to both combined, or whether the recovery might not have occurred spontaneonsly under the unaided vis medicativix naturce. I have felt this difficulty, and still feel it; but it is not so general as to preclude our arriving at certain definite conclusions. For example, I have, as a general rule of conduct, postponed the use of topical remedies, trusting to systemic treatment as lon as the patient appeared to be deriving benefit, and in a certain number of cases cure has appeared to follow; but when, after sufficient trial, $I$ have found no benefit from systemic treatment, or that no further benefit conld be derived from persisting in it, I have had recourse to topical treatment. In numerous cases amendment and cure have immediately or promptly followed. Accumulated experience of this kind has wrought conviction in my mind which no theoretical reasoning can overturn. Carrying the same process yet further, I have arrived at an equally positive conclusion as to the value of potassa fusa. The following case will both illustrate the use of this agent, and the kind of evidence upon which my opinions have been formed.

O_.. Nov. 10th, 1852. Health much reduced by long. standing uterine disease, marked by leucorrhcea, hremorrhagic menstruation, and severe uterine neuralgia; has gone through long courses of general treatment; portio vaginalis projecting congested, enlarged, excessively painful to touch, a velvetty, bleeding surface on os, and dipping into cervical canal; has been treated some months by weekly or fortmightly cauterizations with nitrate of silver; often better, but never well. Potassa fusa to bleeding surface.

17th.-Bleeding surface altered; granulations gone; only redness of spot; no bleeding; feels infinitely less local uneasiness; health better.

Some redness of os and watery discharge continued for some time afterwards. A second application of potassa fusa. Got perfectly well; os presented a round, smooth appearance, without mark of injury. I have seen this patient recently. She has been quite free from pelvic uneasiness, and continues in excellent health.

I submit that no amount of opinion, of authority, or even of negative experience, set forth by those who have never tried or witnessed the use of potassa fusa, ought to prevail with me in opposition to positive evidence of this kind.

Before quitting this subject, I wish to offer another con. sideration. Patients requiring treatment by the more powerful cauteries require it on account of severe intractable surgical disease. It is therefore not to be expected but that in some cases traces of the action either of the disease or of the treatment should persist. Surgery does not, like medicine, usually heal by the subtle operation of remedies acting upon every molecule of the living organism. It heals by ruder means, which not seldom leave their mark.

Caution and candour are also required in drawing conclusions as to the effects of treatment upon patients who come under examination after an interval of time, even short, from the cessation of that treatment. Many causes are constantly operating arnongst women, especially of the poorer classes, to mar and modify the influence of treatment. Some, the moment they feel a little better, abandon treatment, and the disease returns. Some are unable or unwilling to observe the plainest precautions and most imperative injunctions. No one accustomed to case-taking, no one practised in the difficulties of separating reported facts from inferences, but must know how unsafe it is to accept the history of a case of disease as reported by the patient. Nor is it unsafe alone as a basis of pathological conclusions; it is unjust to our brother practitioners who have preceded us in the charge of the patients. The post hoc propter hoc aroument is the test that transcends all others in the popular estimation of methods of treatment. As Dr. Michell, the popular, I trust not the medical, representative of Bodmin, attributes every disease that flesh is heir to to vaccination, because we are vaccinated so early in life that all our nosological misfortunes must follow that event, so there are women who would attribute the origin of cancer itself to an antecedent cauterization.

It may be expected that I should also state my experience as to the etiology and intrinsic importance of uterine diseases. To establish whether, in a particular case, a present physical aterine lesion arose as a primary local affection, or whether it was developed as a secondary result of disease acting in a remote organ or upon the general system, is often a task of considerahle difficulty. But in the course of a careful analysis embracing the histories of many patients, a distinct general conclusion will certainly be eliminated. Such an analysis applied to my own experience tells me that in the production of inflammation, nlceration, and hypertrophy of the uterusexcluding, of course, those cases complicated with tumours and cancer,-conditions having their origin in the uterus itseif occupy the first rank. The first fact in the history of most cases of uterine disease is marriage, childbirth, or abortion. In many cases where uterine disease has persisted for a lengthened period, and in which general debility, spanæmia, dyspeptic, nervous, and other complications exist, it becomes difficult not only to trace out the primary morbid condition, but also to determine what conditions are most active in entertaining the local disease and impairing the general health. We have another question before us. Granted the local uterine disease: Is it capable of working such injurious reactions upon the general system, that it is imperative upon the medical attendant to cure it; or are inflammation, ulceration, and hypertrophy of the uterus of so little account, as some assert, that, per se, they scarcely merit our attention? I have no hesitation in answering that these affections are of real and serious importance; that they cannot be neglected with impunity; that they frequently do involve the most distressing and injurious consequences; and that the medical attendant who neglects the proper and most effectual means of cure, can only be excused on the plea that he does not know or does not appreciate the value of those means.

In thus answering the call of Dr. Boulton, I have done simply what I feel I could not in justice decline. I could not, of course, upon this occasion, enter into an elaborate examination of all the debated questions of uterine pathology and therapeutics. Many questions connected with this interesting subject, including some upon which I differ from Dr. Bennet, I must leave untonched. I have confined myself to giving that testimony for which I have been summoned. If that testimony prove favourable to some of the pathological and therapeutical propositions advanced by Dr. Bennet, which form the immediate subject of controversy, I can only say that it is the result of long and conscientious observation, and given without prejudice 
to any one. I do not imagine that what $I$ have said will have any weight in the solution of those questions. The questions at issue are not to be decided by authority, but by observation. The conviction that is determined by authority is easily acquired, but it is mere prejudice. The conviction that is determined by observation is of slow growth, the fruit of personal labour, but it is the only conviction that thinking men can value. This everyone must acquire for himself.

Devonshire-square, June, 1856.

THE

\section{PHYSIOLOGICAL TEST FOR STRYCHNIA.}

\section{By MARSHALL HALL, M.D., F.R.S., \&c.}

Some years ago several cases of poisoning by arsenic occurred in rapid succession. The career of crime was stayed by its being made publicly known that no poison was so readily or certainly detectible as arsenic.

Arsenic is scarcely more detectible by chemical re-agents than strychnia has proved to be by the physiological test which I recently published in the pages of TrF LANCET.

Recently the 5000th part of a grain has been made manifest to a multitude of beholders at once, and so manifest that no visual object can be more conspicuous-an event very different from the fact of a mere change of colour.

The effect is produced, too, by the simplest means, such as our medical brethren in the country always have at hand.

The common fiog, properly prepared, is not less susceptible of the convulsive effects of galvanism than it is of the pectliar effects of strychnia. Of frogs the smaller ones are more susceptible than the larger, and these should be used recently taken from the pond-from the mud if possible.

The skin should be well dried by means of blotting-paper. The strychnia to be tested should be dissolved in as small a quantity of water as possible, and dropped on the back of the frog, so that it may become absorbed.

Probably a still less quantity of this extraordinary agent may be made manifest if inserted under the skin, or injected into the stomach.

In a short time the frog becomes affected with tetanoid or epileptoid spasm or convulsion on the application of the slightest cause of excitation. It is strychnoscopic.

This susceptible creature may, I am persuaded, be made available for the detection of several other poisons, with each of which the kind and form of the phenomena vary.

Strychnia in the vegetable kingdom answers to the diastaltic spinal system in the animal kingdom, on the centre of which its energies are impressed-a system, the extent of which in the animal economy-next to that of the blood itself-is not even now, after the lapse of nearly a quarter of a century, by any means known or appreciated by the profession!

In this system there is a kind of "solidarite," by which every part is affectible by the excitation of every other:-in reality, the spinal centre is what the great sympathetic was formerly supposed to be! - but there is a speciality too, by means of which one organ may be affected more or less than the rest, thus leading to the difference of form of the phenomena produced, to which I have adverted. The motor branch of the fifth pair is most affected in traumatic tetanus, the laryngeals in strychnism.

I am preparing an essay on the important subject of strychnia as a remedy, a poison, and as a physiological agent.

Princes-street, Hanover-square, June, 1856.

\section{ON SPARGANOSIS, OR MILK ABSCESS.}

\section{By JAMES GILMOUR, M.D., L.R.C.P.}

Srnce MM. Trousseau and Contour published a memoir, ahout fifteen years ago, on the Treatment of Mammary Abscess by Compression, very little has been added by subsequent writers on the abortive, discutient, or repellent method of treating this annoying and perplexing affection.

The management of milk engorgement has heen nearly always slighted by the accoucheur as infra, dig., and left generally to the care of the nurse, and of course she does her best to assist, by fomentations and cataplasms, the process of suppuration, fancying that when this has heen accomplished all trouble and pain will have ended. Alas! this is not always the happy termination.

It is not my intention, in this paper, to give a sletch of the premonitory symptoms which usher in inflammation of the mamma; they are already well described, and as well known; neither do I wish to enter into any useless disquisition with regard to the seat of incipient abscess-viz., whether the congestion, engorgement, or inflammation is located in the proper gland structure, or in the surrounding areolar tissue, fascia, or dermis texture; or whether they be, each or all, involved in the disease. Neither do I inquire if the excitement be limited to one or more of the superficial glands, or may extend to those deeper seated, because I shonld be uselessly repeating that which is remarkably well described by Burns and others; the rationale of treatment about to be described will effect a cure in whatever part of the organ the seat of the disease may be located.

Our great object in threatened milk abscess is to discuss the tumour, and thus prevent suppuration; and our curative indications are, as well expressed by Abernethy, "to remove or mitigate the cause, and to diminish the excited actions by means operating on the system at large, or on the part immediately affected" (Works, vol. iii. p. 31). It was formerly supposed that the abortive treatment of this affection led eventually to the formation and growth of scirrhus and malignant tumours. Etius tells us, in his remarks on emollient remedies, that "violent discutients, which evacuate without softening, do indeed lessen the swelling, but leave afterwards an incurable evil." Benjamin Bell says that in his day the doctrine was pronounced erroneous; and John Hunter set the dispute at rest when he asserted-_I see no reason why inflammation should not as well subside by resolution as by suppuration" ("On the Blood, p. 421)." I am not aware that any author has revived the idea since Hunter's time.

The resolvent method of treating mil' abscess by outward applications is of very ancient origin. Paulus A Egineta "squeezed a soft sponge out of tepid oxycrate, applied to the breasts, and bound it on in a proper form" (Syd. Soc. Ed., vol. i., p. 504). Moschion (who is supposed to have practised at Rome in the days of Nero) advocates the external use of vinegarand-water; and Van Swieten, reasoning in favour of Moschion's views, remarks, "For whilst they are quickly applied at the beginning of inflammation, there is great hope of gently dissipating the inflammation" ("Commentaries,"vol. xiv. sect, 1336). And it may not be out of place here to state that Dewees, in his "Diseases of Females," gives an excellent chapter on the resolvent treatment of milk abscess by externally applying warm vinegar-and-water, but he omits to give either Moschion or Van Swieten any credit for being the originators of the remedy. He evidently gleaned his information from the above source. The reader, curious in these matters, will find a most interesting account how the ancients treated inflammatory tumours by discussives, in Friend's "History of Physic," vol. i., pp. $53-70$.

Nearly all modern writers recommend (in the inflamed condition of the mamma) venesection, leeches to the rart, fomentations and poultices, suction pipes and tubes of all sorts; but, what is more remarkable, they all exhibit (with other reme. dies) saline aperients. Now these, in my opinion, are given most judiciously; and in the method of treatment advocated by me here, they ought not to be omitted. The following summary of discutient remedies, from Samuel Cooper, may not be uninteresting: "Topical blood-letting; saline purges; low diet; keeping the inflamed breast from hanging down; gentle friction with a soft sponge wet with warm emollient liquor; having the milk tenderly sucked out at proper intervals; saturnine applications ; lotions containing muriate of ammonia."

I beg to reintroduce to the notice of the medical profession the treatment of milk abscess by compression, as advocated by Troussean and Contour; the conipression being made with very long strips of adhesive plaster. I give their own words : "The compression is to be accomplished by strips of plaster, broad, and sufficiently long to go several times round the body. The surgeon, standing by the side of the patient, must first fix one of the extremities of the slip at about the middle of the back; then carry it towards the side of the chest; then pass it over the breast, beginning from the lowest part; then obliquely from below apwards to the outer third of the clavicle on the healthy side; and then obliquely downwards across the back, so as to cover the extremity of the slip already tixed. Following this course several times, he must take care that the portion of the band applied each time covers the two upper thirds of the preceding turn. But it is easy to see that if the bandage 